\title{
Factors Affecting Infection and Disease Development on Olive Leaves Inoculated with Fusicladium oleagineum
}

José R. Viruega, Luis F. Roca, Juan Moral, and Antonio Trapero, Departamento de Agronomía, ETSIAM, Universidad de Córdoba, Campus de Rabanales, Edif. C4, 14071 Córdoba, Spain

\begin{abstract}
Viruega, J. R., Roca, L. F., Moral, J., and Trapero, A. 2011. Factors affecting infection and disease development on olive leaves inoculated with Fusicladium oleagineum. Plant Dis. 95:1139-1146.

Infection and development of olive scab disease, caused by Fusicladium oleagineum, were evaluated on detached leaves and potted plants of the susceptible cultivar Picual in growth chambers and a shadehouse. An inoculum dose of $1 \times 10^{5}$ conidia per $\mathrm{ml}$ was selected from a range of densities tested, and it was used for all experiments. Infection occurred from 5 to $25^{\circ} \mathrm{C}$, and disease severity was the greatest at $\sim 20^{\circ} \mathrm{C}$ for wetness durations of 12 to $24 \mathrm{~h}$ and at $\sim 15^{\circ} \mathrm{C}$ for longer durations. Based on a generalized form of the Analytis Beta model, the optimum temperature and minimum wetness duration for infection

tion did not reduce disease incidence but did reduce disease severity. Disease severity was negatively correlated with leaf age. Disease incubation period was positively correlated with leaf age, with a minimum incubation period of 28 days in the youngest leaves. Inoculated plants that were incubated in a growth chamber or in a shadehouse had the same level of infection, but disease severity was lower in plants incubated in the growth chamber because many infections remained latent for 6 months after inoculation. The data in this study will be useful for the development of a forecasting system for olive scab epidemics.
\end{abstract} were $15.5^{\circ} \mathrm{C}$ and $11.9 \mathrm{~h}$. Dry periods $\leq 78 \mathrm{~h}$ immediately after inocula-
Olive scab, which is caused by the fungus Fusicladium oleagineum (Castagne) Ritschel \& U. Braun and is the most important foliar disease of olive (Olea europaea L.), is widespread in many olive-growing regions, including southern Spain (37). The disease, which is also called peacock's eye or leaf spot, was first recognized in Europe in 1845, when its causal agent was described by Castagne in France as Cycloconium oleaginum (33). The teleomorph is unknown but may be a species of Venturia, as is the case for other Fusicladium species (8). F. oleagineum mainly attacks the adaxial surface of the olive leaf, causing typical scab lesions that are often surrounded by yellow haloes and that cause premature leaf drop. Lesions can also occur along the main vein on the abaxial leaf surface and on leaf petioles, fruits, fruit peduncles, and young shoots. Heavy defoliation usually follows severe infection, and recurrent infections cause branch dieback and tree weakness (9). Serious yield losses have been reported $(1,37,41)$. The disease is particularly severe in nurseries and in orchards that are densely planted with susceptible olive cultivars when environmental conditions are favorable (9). New infections are caused by conidia, which are formed in scab lesions and spread by rain droplets. Susceptibility to olive scab often differs among olive cultivars and clones (21). Chemical control of olive scab includes the application of preventive fungicides, especially copper compounds. The use of systemic fungicides is not widespread but has been shown to provide significant disease control $(6,42)$.

Although much research has been done on aspects of olive scab and its control with fungicides $(9,45)$, little information exists on the effects of environmental factors on disease epidemics. In addition to temperature and wind, rainfall is likely a critical factor in most olive scab epidemics (36). Most of this work has been done in the field, and information on the precise effects of environmental variables on olive scab under controlled conditions is scarce and imprecise $(32,45,48)$. Data on how environmental variables affect

Corresponding author: A. Trapero, E-mail: trapero@uco.es

Accepted for publication 26 April 2011.

doi:10.1094/PDIS-02-11-0126

(C) 2011 The American Phytopathological Society disease development are needed to develop a forecasting system and an integrated approach to olive scab control (43). Recently, López-Doncel et al. (22) described a method for inoculating olive with $F$. oleagineum that should facilitate epidemiological studies. This inoculation method, however, has not been tested to study the effects of pathogen and environmental factors on infection and scab development.

The objectives of this study were: (i) to determine the influence of temperature, wetness duration, dry periods after inoculation, and leaf age on infection of olive by $F$. oleagineum; (ii) to use this information to develop mathematical models that describe the relationship between disease severity and environmental variables; and (iii) to standardize conditions and inoculum dose for artificial inoculations with $F$. oleagineum. Preliminary results of this work have been reported $(40,44)$.

\section{Materials and Methods}

Leaves and potted plants. The commercial olive cultivar Picual was used in all experiments. In field evaluations and preliminary experiments under controlled conditions, this cultivar was very susceptible to $F$. oleagineum (21). In all cases except the leaf age experiments, two types of plant material were used: young, detached leaves and 1-year-old rooted olive plants. Detached leaves were obtained from healthy olive plants growing in the greenhouse or from healthy olive trees in the field. Detached leaves were placed in plastic trays between two layers of moistened filter paper immediately after leaves were removed from plants. The plants were propagated from cuttings rooted in perlite and under mist in a commercial nursery. The absence of infection by $F$. oleagineum in these plants was confirmed by the sodium hydroxide method (47) as described in the Disease assessment section. Plants were grown in 3-liter pots containing field soil for 4 to 12 months in a greenhouse at 15 to $30^{\circ} \mathrm{C}$ and were fertilized every 2 weeks with Hoagland's solution (15). Before inoculation, detached leaves and plants were preconditioned for $24 \mathrm{~h}$ at the same temperature to which they would be exposed after inoculation.

Inoculum production. As a biotrophic pathogen, $F$. oleagineum is very difficult to culture in vitro, and in vitro cultures produce few or no conidia $(11,30,32)$. For these reasons, the inoculum used in all experiments was obtained from naturally infected leaves with sporulating scab lesions. From December to March, which is the 
most favorable period for disease development and fungal sporulation on leaves (40), leaves were collected from olive trees severely affected by the disease; the trees were located in Córdoba, Andalusian Province, in southern Spain. The leaves with sporulating lesions were dried at room temperature $(22 \pm$ $2{ }^{\circ} \mathrm{C}$ ) for approximately 7 days and were then placed in plastic bags and maintained at $5^{\circ} \mathrm{C}$ in the dark until they were used in experiments. Under these conditions, conidia from scab lesions remain viable for over 1 year (34).

Conidial suspensions were prepared by dipping leaves with sporulating lesions in distilled water for $2 \mathrm{~h}$ at $5^{\circ} \mathrm{C}$ and then manually shaking the leaves in the water for $2 \mathrm{~min}$. Conidia were separated from leaves and leaf fragments by filtering through a $0.2-\mathrm{mm}$ sieve. The suspensions were adjusted with distilled water to the desired concentrations using a hemacytometer. Tween 20 (one drop per $100 \mathrm{ml}$ ) was added to the inoculum suspensions as a wetting agent. To ensure that the conidia used were viable, germination of each sample of inoculum was measured before each inoculation by placing drops of the conidial suspension on slides, which were placed on covered water agar plates to maintain high humidity. In all inoculations, conidia germination ranged from 50 to $80 \%$. In the experiments on inoculum dose, the stock conidial suspension was adjusted to account for germination rate between experiments.

Inoculation and incubation. Detached leaves and plants were sprayed to incipient runoff with the conidial suspension using an electric sprayer (Black \& Decker 8-102). In all cases except the inoculum dose experiment (see next section), inoculum was adjusted to $1 \times 10^{5}$ conidia per ml. Noninoculated controls for detached leaves and plants were sprayed with distilled water plus Tween 20.

Incubation treatments differed among experiments. Detached leaves were maintained in plastic trays between two layers of moistened filter paper until the end of the experiments. In all cases except the temperature experiment, plastic trays were incubated in dark growth chambers at alternating $20 / 12^{\circ} \mathrm{C}$ daily temperatures and $>70 \% \mathrm{RH}$ for $48 \mathrm{~h}$ and then incubated in the same growth chamber with a 14-h photoperiod and 50 to $90 \%$ RH. In general, plants were incubated during the "wetness period" (which was a variable in the experiments) in moisture chambers that consisted of closed, dark-plastic cages containing plastic pans filled with water to provide $100 \% \mathrm{RH}$. Plastic cages were sprayed with water before use, and after arrangement of the plants, they were placed inside darkened controlled-environment chambers at various constant temperatures with $\mathrm{RH}>70 \%$. After the wetness period, moistened plants were completely dried at room temperature $\left(22 \pm 2^{\circ} \mathrm{C}\right)$ using a fan and a hair drier without heating for $30 \mathrm{~min}$, and they were then transferred to a growth chamber at $12^{\circ} \mathrm{C}$ in the dark and $20^{\circ} \mathrm{C}$ in fluorescent light, with a 14-h photoperiod and 50 to $90 \% \mathrm{RH}$.

Disease assessment. In all experiments, disease severity was determined by assessing visible (scab lesions) and latent infections at the end of the experiment. Latent infections were revealed by immersing leaves in a $5 \%$ sodium hydroxide solution for $30 \mathrm{~min}$ at room temperature $\left(22 \pm 2^{\circ} \mathrm{C}\right)$. After this treatment, visible lesions were more prominent and latent infections appeared as black circular spots or rings, clearly differentiated from healthy green tissue (47). Each leaf was assessed for disease severity with a 0 to 8 rating scale. The scale estimated percentage of leaf surface covered by visible lesions or revealed latent lesions using four main categories or quarters $(\leq 25,26-50,51-75$, and $76-100 \%)$ with two values per each category. Thus, each scale value represents the number of eighths of leaf area covered by lesions which have the following correspondence to affected leaf area: $0=$ no symptoms, 1 $=\leq 12.5 \%, 2=12.6-25 \%, 3=26-37 \%, 4=38-50 \%, 5=51-62 \%$, $6=63-75 \%, 7=76-87 \%$, and $8=88-100 \%$. The scale values $(X)$ were linearly related to the percentage of affected leaf surface $(Y)$ by the equation: $Y=12.5 X-6.25$. A picture of eight olive leaves showing the eight scale values was used to facilitate the assessment. These leaves showed the average of the range of percentage of affected tissue for each scale value (1 to 8), that is, 6, 19, 30, 43, $56,69,81$, and $94 \%$.
Effect of inoculum dose on infection. Inoculum suspensions of $2 \times 10^{3}, 1 \times 10^{4}, 5 \times 10^{4}$, and $2.5 \times 10^{5}$ conidia per ml were sprayed onto olive leaves in trays (three trays per conidial concentration and 30 detached olive leaves per tray). Trays containing inoculated leaves were incubated as described in the Inoculation and incubation section. Disease severity (0 to 8 rating scale) was recorded for each leaf 42 days after inoculation, and the average of each tray (30 leaves) was used for data analysis. This experiment was conducted twice. A randomized complete block design was used with experiments as blocks, inoculum doses as treatments, and trays as replications.

Effect of temperature on infection. Trays containing 30 inoculated detached olive leaves as above were placed in darkened growth chambers at $5,10,15,20$, and $25^{\circ} \mathrm{C}$. After $48 \mathrm{~h}$, the leaves were sprayed with distilled water to remove conidia, and the plastic trays were transferred to a growth chamber for disease development as described in the Inoculation and incubation section. Disease severity was recorded 50 days after inoculation. The experiment was conducted three times. A randomized complete block design was used with experiments as blocks, temperature as the independent variable, and trays as replications.

Effect of wetness duration on infection. Plants inoculated as above were placed in moisture cages in darkened growth chambers at $16^{\circ} \mathrm{C}$. Plants were subjected to a 6-, 12-, 24-, 48-, 96-, or 168-h wetness period. At the end of the wetness period, plants were removed from the moisture cages, dried for $30 \mathrm{~min}$, and then transferred to the growth chamber for disease development as indicated in the Inoculation and incubation section, although in this case $\mathrm{RH}$ was $<70 \%$. In addition to the noninoculated control plants, two inoculated plants were dried immediately after inoculation and transferred to the growth chamber to serve as a 0-h wetness period treatment. Disease severity was recorded 70 days after inoculation. Two plants were subjected to each wetness period, and the experiment was conducted three times. A randomized complete block design was used with experiments as blocks, wetness period as the independent variable, and plants as replications.

Combined effect of temperature and wetness duration on infection. Inoculated plants were placed in moisture cages in darkened growth chambers at $5,10,15,20$, and $25^{\circ} \mathrm{C}$. In each chamber, plants were subjected to 6-, 12-, 18-, 24-, 36-, 48-, and 96-h wetness periods. After plants were removed from the moisture cages, they were dried for $30 \mathrm{~min}$ and then transferred to the same growth chamber for disease development as indicated in the Inoculation and incubation section. In addition to the noninoculated check, two inoculated pots were dried immediately after inoculation and transferred to the growth chamber to serve as a 0 -h wetness period treatment. Disease severity was recorded 70 days after inoculation. Each combination of temperature and wetness duration was applied to two plants, and the experiment was conducted three times. In each repetition of the experiment, the growth chambers were assigned to temperatures at random. A split-plot design was used with experiments as blocks, temperatures as main plots, wetness periods as subplots, and plants as replications.

Effect of postinoculation dry periods on disease severity. Inoculated plants were immediately dried at room temperature $(22 \pm$ $\left.2^{\circ} \mathrm{C}\right)$. After 6-, 78-, and 150 -h dry periods $(<70 \% \mathrm{RH})$ at room temperature, plants were sprayed with distilled water plus Tween 20 and transferred to a shadehouse where they were grown under favorable environmental conditions for scab development (5 to $22^{\circ} \mathrm{C}, 50$ to $100 \% \mathrm{RH}, 946 \mathrm{~h}$ wetness duration, and $327 \mathrm{~mm}$ rain). Noninoculated control plants were sprayed with distilled water plus Tween 20 and were otherwise handled in the same way. Disease incidence (percentage of scab-affected leaves per plant) and severity (rating scale 0 to 8 ) were assessed 75 days after inoculation for visible and latent infections. Each dry period treatment was represented by four replicate plants, and the experiment was performed twice (the plants in the second experiment were inoculated 1 week after those in the first experiment). A randomized complete block design was used with the two experiments as blocks, dry period as the independent variable, and plants as replications. 
Effect of leaf age on disease development. Two experiments were conducted: the first experiment used detached olive leaves and the second used 6-month-old olive plants. In the first experiment, fully expanded leaves from healthy olive trees in the field were separated into two categories: young leaves $(<3$ months old; thin, flexible, and light green) and old leaves ( $>12$ months old; thick, stiff, and dark green). The detached leaves were inoculated and then incubated as described in the Inoculation and incubation section. The incubation period, i.e., the number of days from inoculation until the first scab lesion was observed on each leaf, was assessed every 3.5 days, starting 3 weeks after inoculation. Disease severity was assessed 10 weeks after inoculation. Each leaf category (young and old) was represented by three replicate trays (30 leaves per tray), and the experiment was conducted twice. A randomized complete block design was used with experiments as blocks, leaf age as the independent variable, and trays as replications.

In the second experiment, five shoots were marked on each of four olive plants; each selected shoot had five nodes with two leaves per node (50 leaves per plant). The foliar nodes differed in age by approximately 1 month, i.e., the leaves at the first node from the shoot tip were about 1 month old, while leaves at the fifth node were about 5 months old. Plants were inoculated and incubated for $48 \mathrm{~h}$ in moisture cages placed in the same growth chamber used for the first experiment. After the wetness period, plants were dried and transferred to a growth chamber at the same temperature and $\mathrm{RH}<70 \%$. The incubation period for each pair of leaves of the marked nodes was assessed every 3 days, starting 3 weeks after inoculation. Disease severity was assessed 10 weeks after inoculation based on the mean severity value of each pair of leaves in each node. There were four replicate plants, and the experiment was conducted twice. A randomized complete block design was used with experiments as blocks, leaf age as the independent variable, and plants as replications.

Effect of plant age and postinfection conditions on disease development. Two types of olive plants were used: "young plants" with tender leaves that were $<6$ months old and "old plants" with tough leaves that were $>7$ months old. The young plants were actively growing in a growth chamber. The old plants had been growing in a shadehouse and had some new leaves, but only leaves from the previous year (i.e., leaves that were $>7$ months old) were considered for the experiment. For each plant, five shoots each with five nodes of two leaves (50 leaves per plant) were marked. Leaf age of the marked nodes ranged from 1 to 5 months for the young plants and from 8 to 16 months for the old plants. Plants were inoculated on 15 June and incubated for $48 \mathrm{~h}$ in moisture cages in a growth chamber at $20 / 12^{\circ} \mathrm{C}(14 / 10 \mathrm{~h}$ per day) and $100 \%$ $\mathrm{RH}$ in the dark. After the wetness period, plants were dried and then were subjected to one of two incubation treatments: (i) they were kept in the same growth chamber with a 14-h photoperiod and $\mathrm{RH}<70 \%$, or (ii) they were kept in a shadehouse without environmental control $\left(5-40^{\circ} \mathrm{C} ; 40-100 \% \mathrm{RH}\right.$; $688 \mathrm{~h}$ wetness periods; $133 \mathrm{~mm}$ of rain). The incubation period (time in days between inoculation and the appearance of the first lesion on a pair of leaves at a marked node) was assessed every 3.5 days, starting 3 weeks after inoculation. Disease severity based on visible infections and visible plus latent infections was recorded at the end of the experiment for each pair of leaves at each node. Each treatment (two ages of plants $\times$ two postinoculation environments) was represented by four replicate plants, and the experiment was performed twice (the plants in the second experiment were inoculated 1 week after those in the first experiment). A factorial design was used with the two inoculations as blocks, plant age and incubation conditions as factors, and plants as replications.

Data analysis. Data were analyzed using Statistix 9 (Analytical Software, Tallahassee, FL). Analysis of variance (ANOVA) was performed on disease severity and incubation period data according to the design of each experiment. All experiments were repeated at least once, and data from repetitions of the experiment were combined after checking for homogeneity of the experimental error variances by the $F$ test (two variances) or by the chi-square test (more than two variances). General ANOVAs were applied to the pooled data using experimental runs as blocks. Treatment means were compared by Fisher's protected least significant difference (LSD) at $P=0.05$ for experiments with categorical independent variables or quantitative independent variables with less than four levels, while polynomial contrasts were used for quantitative independent variables with four or more levels. In all experiments, data were tested for normality, homogeneity of variances, and pattern of residuals, which proved their suitability for the statistical analysis without data transformations.

Regression analyses were applied to the pooled means of all independent quantitative variables. Linear regression models were used to describe the relationship between disease severity or incubation period and the inoculum dose, leaf age, and wetness duration. When two factors (plant age and incubation treatment) were combined in the same experiment, a linear regression analysis for each of the four combinations of factors over leaf node was performed and the four adjusted regression lines were compared with each other. Various linear and nonlinear regression models, however, were evaluated for describing the relationship between disease severity and temperature or the combined effect of temperature and wetness duration on disease severity. The models tested were the generic infection model of Magarey et al. (27), Duthie's model (7), the generalized Analytis Beta model (14), the Schödter angular model (14), and several second- or third-order polynomial equations relating to temperature, wetness, and their interaction. All of the regression models used in this study were developed with an empirical approach, that is, the form of the model was determined by the collected data $(5,26)$. A linear regression was applied to test the relationship between data estimated by nonlinear regression and observed data. The best regression model was chosen from many combinations of terms based on the significance of the estimated parameters $(P \leq 0.05)$, Mallow's $\mathrm{Cp}$ statistic, Akaike's information criterion modified for small data sets, the coefficient of determination $\left(R^{2}\right), R^{2}$ adjusted for degrees of freedom $\left(R_{\mathrm{a}}{ }^{2}\right)$, centered $R^{2}$ for no-constant models $\left(R_{\mathrm{c}}{ }^{2}\right)$, the predicted residual sum of squares, and pattern of residuals over predicted and independent variables. For linear regression analysis, the inverse of variance was used as the weight variable (Analytical Software, 5).

\section{Results}

Effect of inoculum dose on infection. Conidial density had a significant $(P=0.0012)$ effect on disease severity, which increased with increasing inoculum concentration from values of 1.9 to 4.5 (scale 0 to 8 ), corresponding to $2.0 \times 10^{3}$ and $2.5 \times 10^{5}$ conidia per $\mathrm{ml}$, respectively. The linear trend was significant $(P=0.0002)$, while quadratic or cubic trends were not significant $(P>0.05)$. The following regression line fit the data well:

$$
S=0.7836 \times \log (I)
$$

in which $S=$ severity of infection (0 to 8$)$ and $I=$ inoculum dose (conidia/ml). The slope parameter was significant $(P<0.0001) ; R^{2}$, $R_{\mathrm{a}}^{2}$, and $R_{\mathrm{c}}{ }^{2}$ were $0.946,0.942$, and 0.745 , respectively; and standardized residuals were randomly distributed over predicted $S$ and $I$.

Effect of temperature on infection. F. oleagineum infected detached leaves at all temperatures tested. Disease severity increased with increasing temperature from 5 to $15^{\circ} \mathrm{C}$ and then decreased from 15 to $25^{\circ} \mathrm{C}$ (Fig. 1). The regression model that best described the influence of temperature on disease severity was the Analytis Beta model (14) according to the following equation:

$$
Y=3.6684 \times t^{0.9364}(1-t)^{1.1062}
$$

in which $Y=$ standardized disease severity $\left(Y=S / S_{\max }\right), t=$ standardized temperature $\left[t=\left(T-T_{\min }\right) /\left(T_{\max }-T_{\min }\right)\right]$, and $k, a$, and $b$ are unknown parameters. $T_{\min }$ and $T_{\max }$ were set equal to 0 and $27^{\circ} \mathrm{C}$, respectively, according to minimal and maximal temperatures for conidia germination $(30,34)$. The above equation can be rewritten as:

$$
S=0.018 \times T^{0.9364} \times(27-T)^{1.1062}
$$


in which $S=$ disease severity ( 0 to 8 ) and $T=$ temperature $\left({ }^{\circ} \mathrm{C}\right)$. All estimated parameters of the equation were significant $(P<0.0001)$; $R^{2}, R_{\mathrm{a}}{ }^{2}$, and $R_{\mathrm{c}}{ }^{2}$ were $0.982,0.978$, and 0.879 , respectively; and the standardized residuals were randomly distributed over predicted $Y$ and $t$. The predicted temperature of maximum disease severity was $12.4^{\circ} \mathrm{C}$. At this temperature, the maximum estimated disease severity was 3.7 with confidence and prediction intervals of 3.3 to 4.2 and 2.3 to 6.1 , respectively.

Effect of wetness duration on infection. Disease severity was significantly influenced by wetness duration. No infection was detected when the wetness duration was $<12 \mathrm{~h}$. From 12 to $168 \mathrm{~h}$ of wetness, a linear relationship between severity of infection $(S, 0$ to 8 ) and duration of wetness period ( $W,>12 \mathrm{~h}$ ) was observed, according to the equation:

$$
S=0.015 \times W
$$

The slope parameter was significant $(P=0.0003) ; R^{2}, R_{\mathrm{a}}{ }^{2}$, and $R_{\mathrm{c}}{ }^{2}$ were $0.989,0.984$, and 0.915 , respectively; and standardized residuals were randomly distributed over predicted $S$ and $W$. This model should not be used to predict disease severity when the wetness duration is $<12 \mathrm{~h}$.

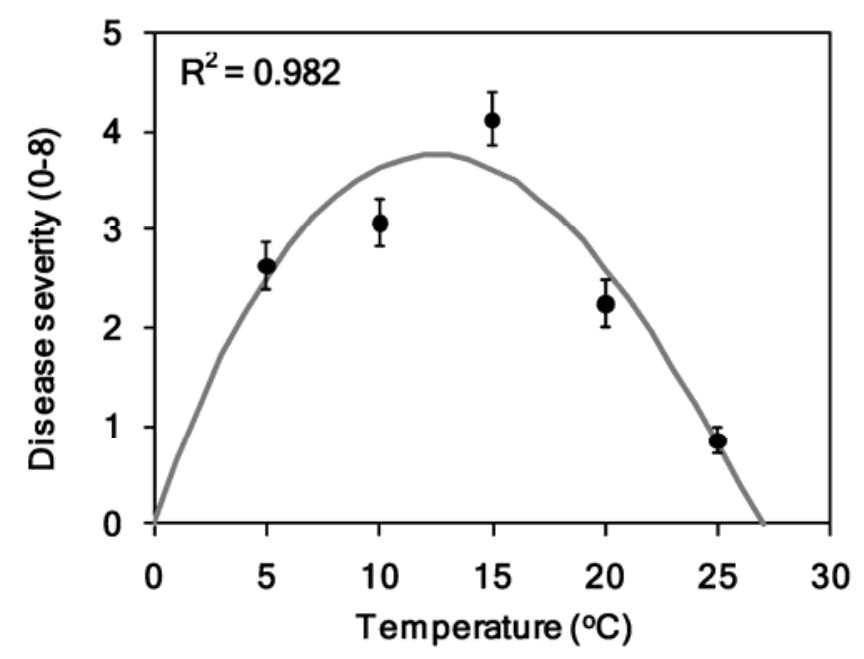

Fig. 1. Effect of temperature on disease severity on detached olive leaves inoculated with Fusicladium oleagineum and incubated under continuous wetness. The curve represents the Analytis Beta function $S=0.018 \times T^{0.9364} \times(27-T)^{1.1062}$ relating disease severity $(S, 0$ to 8$)$ with temperature $\left(T, 0\right.$ to $\left.27^{\circ} \mathrm{C}\right)$. Points are the observed means of 180 leaves with their standard errors. The equation fit the observed data with $R^{2}=0.982$.

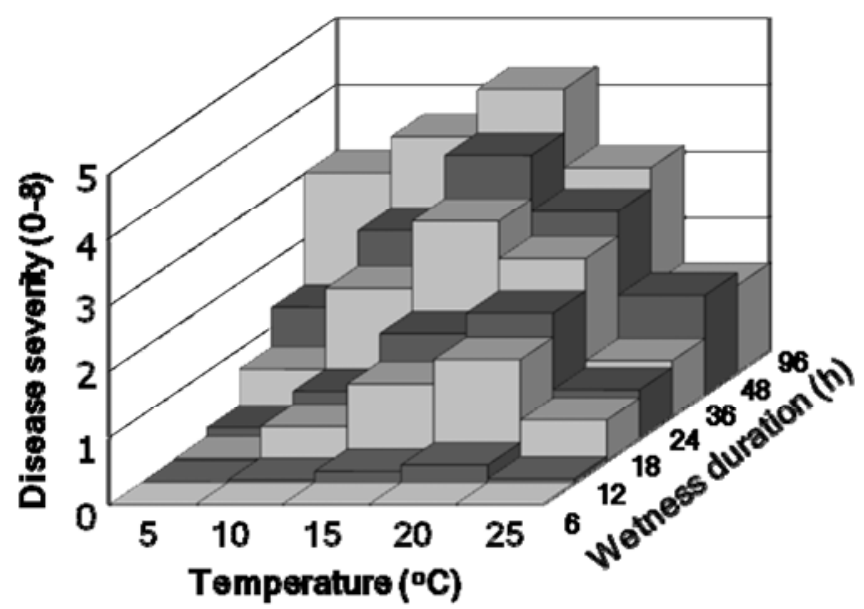

Fig. 2. Effects of temperature and wetness duration on disease severity in olive plants inoculated with Fusicladium oleagineum. Each bar represents the mean disease severity of nine plants that were assessed with a rating scale $(0$ to 8$)$ applied to each leaf.
Combined effect of temperature and wetness duration on disease severity. Disease severity was significantly affected by temperature, wetness duration, and their interaction. Disease severity increased with increasing wetness duration for wetness periods $>12 \mathrm{~h}$ (Fig. 2). The effect of the duration of the wetness period depended on temperature. For wetness periods $\leq 24 \mathrm{~h}$, disease severity was greatest from 10 to $20^{\circ} \mathrm{C}$, and the maximum was probably near $20^{\circ} \mathrm{C}$. For wetness periods $>24 \mathrm{~h}$, disease severity was greatest near $15^{\circ} \mathrm{C}$. At $5^{\circ} \mathrm{C}$, infections were detected only for wetness periods $>18 \mathrm{~h}$.

Several linear and nonlinear models were evaluated to analyze the combined effect of temperature and wetness duration on disease severity. The best and simplest regression model describing the influence of temperature and wetness duration on disease severity was the generalized Analytis Beta model:

$$
Y=\mathrm{k} \times t^{\mathrm{a}} \times(1-t)^{\mathrm{b}} \times\left(W-W_{0}\right)^{\mathrm{c}}
$$

in which $Y=$ standardized disease severity ( 0 to 1$), t=$ standardized temperature $\left(T-T_{\min }\right) /\left(T_{\max }-T_{\min }\right)$ during the wetness duration, $W$ = wetness duration $(\mathrm{h}), W_{0}=$ minimum wetness duration for infection, and $k, a, b$, and $c$ are unknown parameters. $T_{\min }$ and $T_{\max }$ were fixed to 0 and $27^{\circ} \mathrm{C}$, respectively, according to minimal and maximal temperatures for conidia germination $(30,34)$. The equation adjusted for the observed data was:

$$
Y=0.531 \times t^{1.2018} \times(1-t)^{0.8944} \times(W-11.9)^{0.4714}
$$

This equation can also be rewritten as:

$$
S=2.263 \times 10^{-3} \times T^{1.2018} \times(27-T)^{0.8944} \times(W-11.9)^{0.4714}
$$

where $S=$ severity of infections $(0$ to 8$)$ and $T=$ temperature $\left({ }^{\circ} \mathrm{C}\right)$. All estimated parameters of the equation were significant $(P<$ $0.05) ; R^{2}, R_{\mathrm{a}}^{2}$, and $R_{\mathrm{c}}^{2}$ were $0.957,0.955$, and 0.892 , respectively; and standardized residuals were randomly distributed over predicted $Y, T$, and $W$. The relationship between $W$ and $T$ for different levels of disease severity is described by the contour plot in Figure 3. The optimum temperature predicted by the model was $15.5^{\circ} \mathrm{C}$. At this temperature, disease severity values of $25,50,75$, and $100 \%$ were predicted for wetness durations of $16.2,30.2,55.1$, and $91.4 \mathrm{~h}$, respectively. The predicted minimum wetness duration for infection was $11.9 \mathrm{~h}$.

Effect of postinoculation dry periods on disease severity. The incidence and severity of visible and latent infections were influenced by dry treatments applied immediately after inoculation

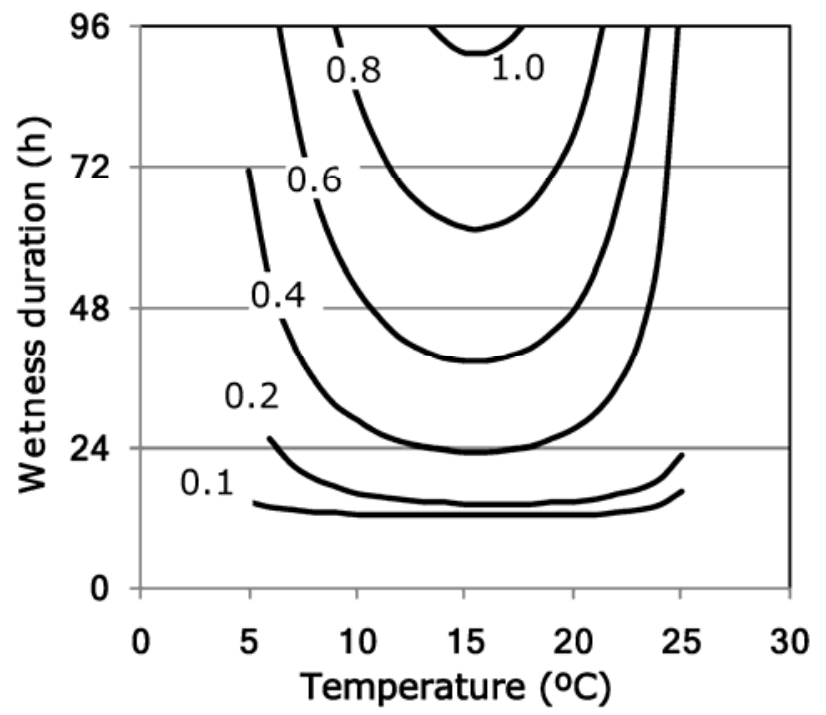

Fig. 3. Contour plot of proportion of disease severity for different combinations of temperature $(T)$ and wetness duration $(W)$ as predicted by model $f(W, T)=0.531 \times$ $10^{3} \times T^{1.2018} \times(27-T)^{0.8944} \times(W-11.9)^{0.4714}$ for data from Figure 2. The model fit the observed data with $R^{2}=0.975$. Each line (isopath) depicts a contour line connecting points of equal proportions of disease severity. 
(Table 1). The percentage of infected leaves per plant (i.e., incidence of infection) did not differ for the $0-, 6-$, or 78-h dry periods, but the percentage was reduced for the 150-h treatment. Severity of visible infections, however, decreased as the length of dry periods increased. This linear trend was also observed for severity of total infections (visible plus latent), although the difference between 0and 6-h dry periods was not significant (Table 1).

Effect of leaf age on disease development. Leaf age significantly $(P<0.0001)$ influenced the incubation period $(I P)$ and disease severity $(S)$ in detached leaves from olive trees. IP ranged from 31 days in young leaves to 64 days in old leaves. $S$ ranged from 3.8 in young leaves to 0.5 in old leaves. In inoculated plants, $I P$ was positively correlated and $S$ was negatively correlated with leaf age (foliar node) (Fig. 4). The relationships between IP or $S$ and leaf age were described by the equations:

$$
I P=25.0+5.1 \times N ; S=5.0-0.72 \times N
$$

where $I P=$ incubation period (days), $S=$ disease severity ( 0 to 8 rating scale) at the end of the experiment, and $N=$ leaf node ( 1 to $5 ; 1=$ youngest and $5=$ oldest $)$. All regression parameters were significant $(P<0.01) ; R^{2} / R_{\mathrm{a}}{ }^{2}$ were $0.961 / 0.948$ and $0.954 / 0.938$ for $I P$ and $S$, respectively; and standardized residuals were randomly distributed over predicted $I P$ or $S$ and the independent variable $N$.

Effect of plant age and postinfection incubation treatment on disease development. The incubation period $(I P)$ was significantly $(P<0.0001)$ affected by incubation treatment (plants kept in growth chamber or in shadehouse) and plant age, but the interaction between these factors was not significant $(P=0.644) . I P$ was more affected by incubation treatment than by plant age, i.e., plants incubated in the growth chamber had much shorter $I P$ values than plants incubated in the shadehouse (Fig. 5A). For each incubation treatment, $I P$ was shorter for young plants than for old plants. For each plant age and incubation treatment, $I P$ was positively correlated with leaf age (node), and the four $I P$ regressions (one for each combination of two plant ages and two incubation treatments) were significantly different from each other (Table 2).

Disease severity $(S)$ assessed as visible infections (scab lesions) at the end of the experiment was significantly $(P<0.0001)$ affected by both incubation treatment and plant age, but the interaction between these factors was not significant $(P=0.162)$. The effect of incubation treatment was greater than the effect of plant age. Regardless of plant age, $S$ values were higher for plants kept in the shadehouse than for plants kept in the growth chamber. Regardless of incubation treatment, $S$ values were higher for young plants than for old plants (Fig. 5B).

When disease severity $(S)$ was calculated as the sum of visible and latent infections, the effects of incubation treatment and the interaction between incubation treatment and plant age were not

Table 1. Effect of a postinoculation dry period on incidence and severity of leaf infection in olive plants inoculated with Fusicladium oleagineum

\begin{tabular}{lcclcc}
\hline & \multicolumn{2}{c}{ Incidence $(\%)^{\mathbf{x}}$} & & \multicolumn{2}{c}{ Severity $(\mathbf{0 - 8})^{\mathbf{y}}$} \\
\cline { 2 - 3 } \cline { 5 - 6 } Dry period (h) & Visible & Total & & Visible & Total \\
\hline 0 control) $^{n}$ & $42 \mathrm{a}^{\mathbf{z}}$ & $82 \mathrm{a}$ & & $2.1 \mathrm{a}$ & $2.8 \mathrm{a}$ \\
78 & $51 \mathrm{a}$ & $98 \mathrm{a}$ & & $1.5 \mathrm{~b}$ & $3.2 \mathrm{a}$ \\
150 & $44 \mathrm{a}$ & $96 \mathrm{a}$ & & $0.9 \mathrm{c}$ & $1.8 \mathrm{~b}$ \\
\hline
\end{tabular}

${ }^{\mathrm{w}}$ Immediately after inoculation, plants were dried with a fan and then grown in a shadehouse for 10 weeks.

${ }^{x}$ Percentage of leaves per plant with visible scab symptoms or visible infection + latent infections (Total). Latent infections were assessed by the sodium hydroxide method (47).

${ }^{\mathrm{y}}$ Disease severity was assessed using a rating scale of 0 to $8(0=$ no lesions, $8=88-100 \%$ of leaf surface covered with scab lesions or latent infections).

${ }^{\mathrm{z}}$ Data are the average of two experiments with four plants per experiment. For each column, means with the same letter are not significantly different according to Fisher's protected LSD test at $P=0.05$. There was a significant negative linear trend for disease severity data. significant $(P>0.05)$. Only plant age was significant $(P=0.004)$, i.e., $S$ values were higher for young plants than for old plants (Fig. 5C). For each plant age and incubation treatment, $S$ was negatively correlated with leaf age (node), and the two regressions fitted for young plants differed significantly $(P<0.001)$ from the two regressions fitted for old plants, but the regressions did not differ $(P$ $>0.05$ ) within each plant age (Table 2).

\section{Discussion}

The current study is the first to report the influence of $F$. oleagineum inoculum concentration, temperature, wetness duration, dry periods after inoculation, leaf age, and incubation conditions on development of olive scab under controlled conditions. Previous studies of olive scab have been hampered by the lack of a reproducible method for $F$. oleagineum inoculation and by the failure to control environmental variables $(24,45,48)$. A reproducible method for inoculating olive plants with $F$. oleagineum was developed by López-Doncel et al. (22). This method has been used to assess cultivar resistance (21), pathogenic variability of the fungus (20), the infection process (3), and efficacy of biological and chemical control products $(31,42)$.

In this study, we validated this inoculation method by determining major factors affecting the responses of inoculated plants. Other important factors not included in this study, such as the source and maintenance of inoculum or the preparation of plant material, were established during the development of the inoculation method (22). Unfortunately, experimental inoculation of $F$. oleagineum requires the use of conidia from naturally infected leaves, which probably introduces significant variation into the results obtained with different inoculum preparations. The development of methods for in vitro production of $F$. oleagineum conidia would greatly facilitate research on olive scab, as it did in a similar pathosystem, apple scab caused by Venturia inaequalis (anamorph: Fusicladium pomi) (25). The olive scab pathogen, however, grows very poorly in artificial media, and so far all attempts to get abundant sporulation have failed (11,34; A. Trapero, unpublished data).

Infection and scab development were similar with detached leaves and intact plants, confirming a previous report that detached leaves could be used to study this disease (43). The use of detached leaves rather than plants saves space and time. Detached leaves, however, must be carefully managed to prevent contamination and rapid deterioration as reported by López-Doncel et al. (22).

Although conidial inoculum dose influenced disease severity in the current study, differences among inoculum doses were not large, probably due to the low level of infection in our experiment

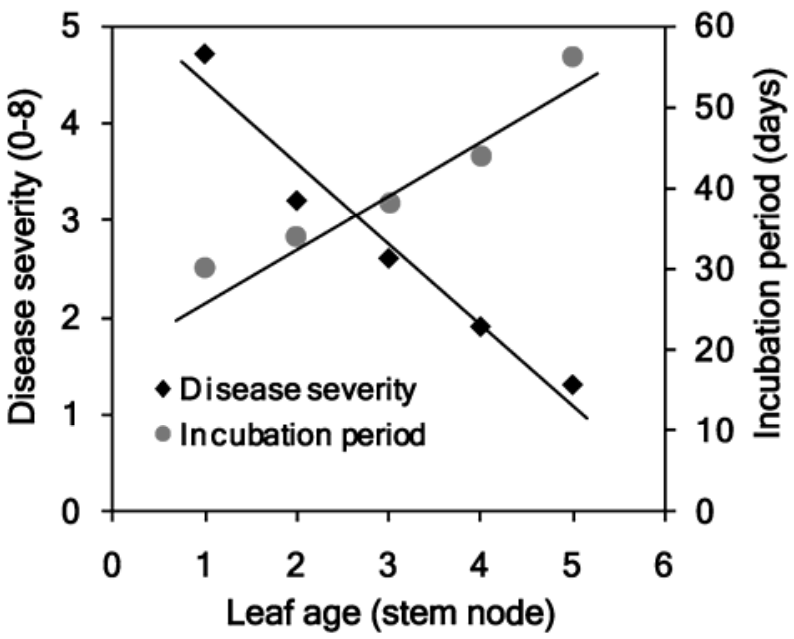

Fig. 4. Effect of leaf age (leaf node) on incubation period $(I P)$ and disease severity (S) for olive plants inoculated with Fusicladium oleagineum. Lines represent linear regression of $I P$ and $S$ over foliar node (equivalent to age in months). Values are the observed means of 50 foliar nodes per plant and eight plants. The linear regression lines fit the observed data with $R^{2}=0.961$ for $I P$ and $R^{2}=0.954$ for $S$. 
and the rating scale used for disease severity assessments. Counting the number of lesions would be more accurate than disease severity to distinguish between inoculum doses, but the number of lesions was not feasible to count when disease severity was equal to or higher than 4 (38 to $50 \%$ ) because many lesions overlapped. Additionally, the number of lesions was not linearly related to the affected leaf area (disease severity), because lesion size decreased
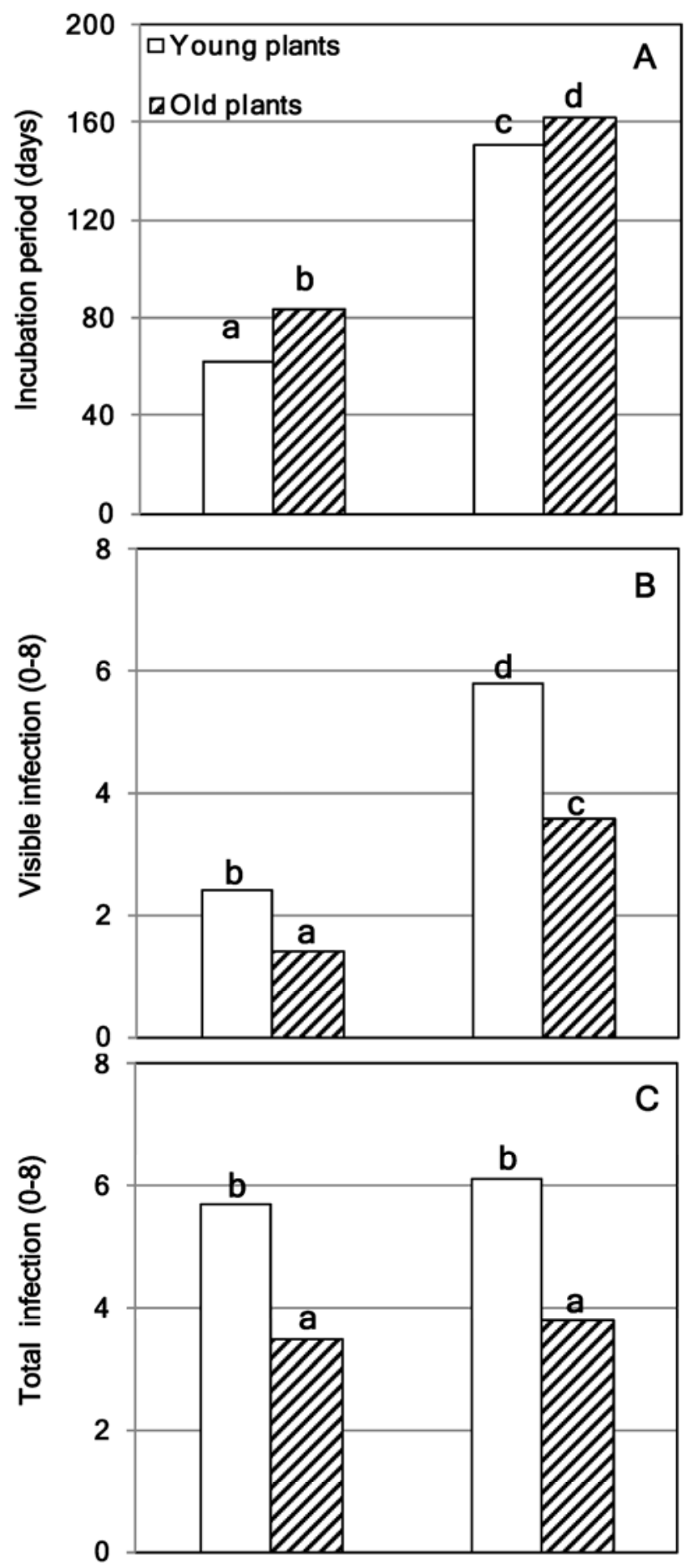

\section{Growth chamber Shadehouse}

Fig. 5. Effect of plant age and postinfection incubation conditions on $\mathbf{A}$, incubation period, B, severity of visible infection (scab lesions), and C, total infection (visible plus latent infections) for olive plants inoculated with Fusicladium oleagineum. Each bar represents the mean of 50 foliar nodes per plant and eight plants. Bars with the same letter are not significantly different according to Fisher's protected LSD test at $P=0.05$. with increasing number of lesions (A. Trapero, unpublished observations), and the purpose of the rating scale was to assess the leaf area covered by lesions. Given the positive relationship between inoculum concentration and disease severity, greater disease would probably have been produced with inoculum concentrations $>2.5 \times$ $10^{5}$ conidia per $\mathrm{ml}$, which was the highest concentration used in this study. Obtaining the large number of conidia needed for such high densities is not feasible, however, when the conidia are obtained from leaf lesions (20). In the few existing studies on inoculation of olive leaves with $F$. oleagineum, inoculum doses (conidia per ml) were $1 \times 10^{5}(24), 2 \times 10^{6}(48), 4 \times 10^{6}(19)$, or unstated $(28,45)$. Zayed et al. (48) did not indicate how they obtained an inoculum dose $\geq 10^{6}$ conidia per ml. Longo et al. (19) incubated the sporulating olive leaves in a moisture chamber for 24 $\mathrm{h}$ before inoculation. These conditions, however, were unfavorable for inoculum production because some conidia germinated on the scab lesions and some saprophytic fungi were growing on leaves (20). Based on our results and on the difficulty in obtaining high numbers of conidia from infected leaves, we considered an inoculum suspension of $1.0 \times 10^{5}$ conidia per $\mathrm{ml}$ to be satisfactory for routine experimental inoculation of olive plants with $F$. oleagineum. In a previous study of apple scab, $2.5 \times 10^{5}$ conidia of $V$. inaequalis per $\mathrm{ml}$ was the highest inoculum dose used (13).

The infection of olive leaves by $F$. oleagineum was influenced by temperature and wetness duration, which has also been demonstrated for other foliar fungal pathogens $(12,46)$. When wetness was not a limiting factor, inoculation of detached leaves showed that infection occurs between 5 and $25^{\circ} \mathrm{C}$. The Analytis Beta function (14) was useful for describing the relationship between infection and temperature. According to this function, the optimum temperature for infection was $12.4^{\circ} \mathrm{C}$. This value is within the range of 10 to $15^{\circ} \mathrm{C}$ determined by other authors to be optimal for germination of $F$. oleagineum conidia $(29,30,34)$. The inoculation of olive plants at the highly favorable daily temperature regime of $20 / 12^{\circ} \mathrm{C}$ revealed a linear relationship between severity of infection and wetness period. No infections were detected with $<12 \mathrm{~h}$ of wetness, and the infection level with $12 \mathrm{~h}$ of wetness was very low, suggesting that $12 \mathrm{~h}$ could be considered the minimum wetness duration for infection of olive leaves at favorable temperatures. This represents an uncommonly long "minimal wetness period for infection" among foliar fungal pathogens; for example, the minimum wetness period for $V$. inaequalis is $6 \mathrm{~h}$ (27). Also, a linear relationship between infection and wetness duration that does not reach a maximum value (an asymptote) is rare (27), although the low level of infection in this experiment could explain this anomalous result.

Because the effects of wetness duration and temperature are interdependent, these factors should be considered together $(5,7)$. In the present study, wetness duration was the major factor influencing foliar infection by $F$. oleagineum, but its effect was influenced by temperature. For wetness periods $\leq 24 \mathrm{~h}$, the optimum temperature was around $20^{\circ} \mathrm{C}$, but for wetness periods $>24 \mathrm{~h}$, the optimum was about $15^{\circ} \mathrm{C}$. A generalized form of the Analytis Beta model accurately described the observed data, and it was selected because of its simplicity and the biological significance of its parameters; both characteristics are useful for understanding the infection process (5). The optimum temperature predicted by the fitted model $\left(15.5^{\circ} \mathrm{C}\right)$ was higher than the optimum temperature $\left(12.4^{\circ} \mathrm{C}\right)$ found in the continuous wetness experiment. The unlimited wetness period in the latter case may account for a higher disease severity at low temperatures. The minimum wetness period, however, was the same in both experiments, confirming that the pathogen requires long ( $\geq 12 \mathrm{~h}$ ) wetness periods to infect olive leaves.

As noted earlier, previous reports about the influence of wetness duration and temperature on olive scab come from field observations (9) or from spore germination studies $(29,30,32,45)$, but seldom from experiments in which plants were inoculated and maintained under controlled conditions $(24,28)$. Most of these studies indicate that infection of olive leaves by $F$. oleagineum requires long wetness periods as regulated by temperature, although the 
studies differ regarding the details of wetness duration and temperature. Modugno (28) reported minimum wetness periods for infection of olive leaves of 36,24 to 36,18 , and 14 h at 5, 12, 18, and $24^{\circ} \mathrm{C}$, respectively. In germination studies on olive leaves, Saad and Masri (32) indicated that wetness periods of 48, 24, and 36 $\mathrm{h}$ were required for appressorium formation at 16,20 , and $24^{\circ} \mathrm{C}$, respectively, but wetness periods of only 9 to $24 \mathrm{~h}$ have been reported as requirements for conidial germination (29). Longer and shorter wetness durations than those found in our study were reported for naturally infected plants under field conditions $(4,24,28,36)$, but these observations should be considered with caution because the exact time of infection and the effects of cultivar susceptibility or environmental conditions were often unknown.

In the current study, a few infections occurred on inoculated plants that did not receive a wetness period. Similarly, dry periods that began immediately after inoculation had a limited effect on infection. Even for the longest dry period of $150 \mathrm{~h}$, severity of infections was reduced only six times relative to plants that were not subjected to a dry period. This result is unusual $(16,27)$, although it has been observed for other diseases $(25,39)$. Conidia of $F$. oleagineum are reported to survive adverse environmental conditions for relatively long periods (18). The ability of $F$. oleagineum conidia to produce some infection in the absence of a wet period and to survive adverse conditions could have important epidemiological consequences.

Artificial inoculations of detached leaves and olive plants revealed that younger, less cutinized leaves were more susceptible than older ones. The incubation period of scab disease was about two to four times shorter on the youngest leaves than on the oldest leaves, and disease severity was three to five times higher for the youngest than for the oldest leaves. Our results indicate that disease severity is linearly and negatively related to leaf age. These results should resolve the controversy about the relationship between leaf age and susceptibility to olive scab. Some authors have stated that the old leaves are more susceptible than young leaves based on field observations $(2,30,45)$, while others have indicated that young leaves are more susceptible than old leaves $(10,17,23,36)$. Our results, which were replicated and obtained under controlled conditions, indicate that the latter reports are correct. Probably the long incubation period of infections may account for these discrepancies in observations under field conditions.

The decrease of olive scab severity with increasing leaf age is a case of ontogenic resistance, or age-related resistance, which has been reported for many plant diseases including apple scab (25). Ontogenic resistance describes the ability of whole plants or plant parts to resist or tolerate disease as they age and mature. The nature of ontogenic resistance in other pathosystems has been associated with various physical and chemical features of the leaf cuticle or with host substances induced or favored by infection (25). In olive, researchers have reported a lower rate of conidium germination on old than on young leaves $(29,34)$, which would reduce the susceptibility of old leaves in terms of numbers of lesions produced. In addition, a reduced rate of conidium germination, germ tube elongation, and cuticle penetration has been identified as a resistance mechanism in young leaves of the olive cultivar Lechín de Sevilla (3).

The results reported here increase our understanding of the disease cycle and epidemiology of olive scab. Because young olive leaves are susceptible to infection and because most young olive leaves develop during spring, spring is particularly important for primary infection. If rain is frequent and temperatures are mild during spring, and if scab lesions are abundant on old leaves, severe epidemics may occur. The great importance of spring infection for olive scab epidemics has been emphasized by others $(35,38,43)$ based on the extreme susceptibility of young leaves that are not protected by fungicides (38). Spring infections usually remain latent until the next fall or winter, when environmental conditions allow the development of scab lesions (43).

In addition to being influenced by leaf age, the incubation period of olive scab, equivalent to a latent period, was influenced by environmental conditions after infection. The longest incubation periods ( $>174$ days) were observed on the oldest leaves on old plants inoculated at the end of spring and maintained under natural conditions in a shadehouse; the shortest incubation periods (about 30 days) occurred with the youngest leaves on young plants that were kept in a growth chamber. Results in the present study agree with those obtained by Loprieno and Tenerini (24), who inoculated olive plants of the cultivar Corregiolo with $F$. oleagineum and then maintained the plants under natural conditions. Given that the incubation period for this disease is long even under favorable conditions, a maximum of 3 to 4 disease cycles per year is possible in the Mediterranean climate, and these cycles would mainly occur from winter to spring. This biotrophic fungus apparently survives the long, dry, and warm Mediterranean summer in latent infections (38). Factors determining the change from latent infection to active scab lesion are not known, but leaf wetness seems essential, as suggested by the differences between plants that were incubated in a growth chamber (without wetness) and those incubated in a shadehouse ( $688 \mathrm{~h}$ wetness); latent infections were much less numerous in the wet environment. Field observations are also consistent with this hypothesis because scab lesions appear after long periods of wetness $(4,24,28,43)$.

Although results of the present study agree with some field observations $(4,9,36,43)$, it is often difficult to compare field studies on the effects of environmental conditions on disease development

Table 2. Effect of plant age and postinfection incubation conditions on the incubation period and disease severity of olive plants inoculated with Fusicladium oleagineum

\begin{tabular}{|c|c|c|c|c|c|c|}
\hline \multirow[b]{2}{*}{ Dependent variable $^{v}$} & \multirow[b]{2}{*}{ Plant age $^{w}$} & \multirow[b]{2}{*}{ Incubation $^{x}$} & \multicolumn{4}{|c|}{ Linear regression parameters ${ }^{y}$} \\
\hline & & & $a$ & $b$ & $R^{2}$ & $P$ \\
\hline \multirow[t]{4}{*}{ Incubation period $(I P)$} & \multirow[t]{2}{*}{ Young } & Growth chamber & $55.25 \mathrm{a}^{\mathrm{z}}$ & $2.82 \mathrm{a}$ & 0.957 & 0.0037 \\
\hline & & Shadehouse & $135.18 \mathrm{c}$ & $4.72 b$ & 0.972 & 0.0020 \\
\hline & \multirow[t]{2}{*}{ Old } & Growth chamber & $73.91 \mathrm{~b}$ & $2.97 \mathrm{a}$ & 0.938 & 0.0065 \\
\hline & & Shadehouse & $146.53 \mathrm{~d}$ & $5.51 \mathrm{~b}$ & 0.993 & 0.0002 \\
\hline \multirow[t]{4}{*}{ Disease severity $(S)$} & \multirow[t]{2}{*}{ Young } & Growth chamber & $7.6 \mathrm{~b}$ & $-0.67 b$ & 0.924 & 0.0129 \\
\hline & & Shadehouse & $7.9 \mathrm{~b}$ & $-0.63 \mathrm{~b}$ & 0.941 & 0.0044 \\
\hline & \multirow[t]{2}{*}{ Old } & Growth chamber & $4.5 \mathrm{a}$ & $-0.34 \mathrm{a}$ & 0.823 & 0.0165 \\
\hline & & Shadehouse & $5.0 \mathrm{a}$ & $-0.39 \mathrm{a}$ & 0.876 & 0.0238 \\
\hline
\end{tabular}

v The incubation period $(I P)$ for each plant was calculated as $I P=\sum\left[\left(n_{i}-n_{i-1}\right) \times t_{i}\right] / N$, where $n_{i}-n_{i-1}$ is the number of affected leaves between two successive assessments, $t_{i}$ is the time in days from inoculation, and $N$ is the total number of assessed leaves. Disease severity ( $S$ ) was assessed at the end of experiment using a rating scale of 0 to $8(0=$ no lesions, $8=88-100 \%$ of leaf surface covered with scab lesions or latent infections).

${ }^{\text {w }}$ Plants were classified into two categories: young (tender leaves, $<6$ months old) and old (tough leaves, $>7$ months old).

${ }^{x}$ After a 48-h infection period, plants were dried and then were subjected to one of two incubation treatments: growth chamber $\left(20 / 12^{\circ} \mathrm{C}\right.$ day/night, $<70 \%$ $\mathrm{RH})$ and shadehouse $\left(5-40^{\circ} \mathrm{C} ; 40-100 \% \mathrm{RH} ; 688 \mathrm{~h}\right.$ wetness periods; $133 \mathrm{~mm}$ of rain).

${ }^{y} I P$ and $S$ data were adjusted to a linear regression model: $Y=a+b \mathrm{X}$, in which $Y=I P$ or $S, a$ is the constant, $b$ is the slope coefficient, $\mathrm{X}$ is the foliar node (equivalent to age in months), $R^{2}=$ coefficient of determination, and $P=$ probability value.

${ }^{\mathrm{z}}$ Data are the average of two experiments with four plants per experiment. For each dependent variable and regression coefficient, means with the same letter are not significantly different according to the comparison of regression lines test (Statistix 9). 
with those conducted in growth chambers where only one infection cycle occurs. However, under field conditions, it is possible to reach a high level of infection after only one infection cycle when healthy olive plants are exposed to abundant inoculum for short periods of time (J. R. Viruega, L. F. Roca, J. Moral, and A. Trapero, unpublished). This situation may account for the explosive nature of the disease when the weather is wet, temperatures range from 10 to $20^{\circ} \mathrm{C}$, and primary inoculum is abundant (38). In our study, $50 \%$ disease severity required 30 to $39 \mathrm{~h}$ at these temperatures. In the Mediterranean climates where olives are grown, continuous wet periods of 1 to 3 days are frequent in the late fall and winter when most olive leaves are old and therefore have reduced susceptibility, but they are uncommon in the spring when most of the highly susceptible new leaves develop. The pathogen, however, may tolerate intermittent dry periods during the infection process, as indicated by our data on the effect of dry periods after inoculation.

The present study has quantified the effects of environmental and host factors on infection and scab development in olive leaves. The results should help pest managers and researchers predict the risk of olive scab in different regions or under different crop management practices. The results will also be useful for the development of a disease forecasting system for the proper timing of foliar fungicidal sprays.

\section{Acknowledgments}

This research was supported by projects AGF93-0342 and AGF96-1082 from the CICYT, the Spanish Ministry of Education and Science, and project AGR03635 from DGPA, Andalusia Regional Government. We thank F. Luque Márquez for her valuable technical assistance and W. J. Kaiser and B. Jaffee for critical review of the manuscript.

\section{Literature Cited}

1. Andrés, F. De. 1991. Enfermedades y plagas del olivo. 2a ed. Riquelme y Vargas Ediciones, Jaén, Spain.

2. Andreucci, E., and Bonifacio, A. 1962. Richerche su Cycloconium oleaginum in alcune zone della Toscana Settentrionale. Phytopathol. Mediterr. 1:141-151.

3. Benítez, Y., Botella, M. A., Trapero, A., Alsalimiya, M., Caballero, J. L., Dorado, G., and Muñoz-Blanco, J. 2005. Molecular analysis of the interaction between Olea europaea and the biotrophic fungus Spilocaea oleagina. Mol. Plant Pathol. 6:425-438.

4. Benito, J. 1984. Precisiones para un mejor conocimiento de algunas enfermedades del olivo. I Symposium Nacional de Agroquímicos, Sevilla, Spain.

5. Campbell, C. L., and Madden, L. V. 1990. Introduction to Plant Disease Epidemiology, John Wiley \& Sons, New York.

6. Corda, P., Maddau, L., and Marras, F. 1993. Systemic fungicide residues in oil from field-treated olive. EPPO Bull. 23:399-404.

7. Duthie, J. A. 1997. Models of the response of foliar parasites to the combined effects of temperature and duration of wetness. Phytopathology 87:1088-1095

8. González-Lamothe, R., Segura, R., Trapero, A., Baldoni, L., Botella, M. A., and Valpuesta, V. 2002. Phylogeny of the fungus Spilocaea oleagina, the causal agent of peacock leaf spot in olive. FEMS Microbiol. Lett. 210:149155.

9. Graniti, A. 1993. Olive scab: A review. EPPO Bull. 23:377-384.

10. Guechi, A., and Girre, L. 1994. Sources of Cycloconium oleaginum (Cast.) conidia for infection of olive leaves and conditions determining leaf spot disease development in the region of Sétif, Algeria. Mycopathologia 125:163-171.

11. Gutiérrez-Paulano, F. 1998. Factores que influyen en el crecimiento in vitro de Spilocaea oleagina. Trabajo Profesional Fin de Carrera, ETSIAM, Universidad de Córdoba, Córdoba, Spain.

12. Harrison, J. G., Lowe, R., and Williams, N. A. 1994. Humidity and fungal diseases of plants-problems. Pages 79-97 in: Ecology of Plant Pathogens. J. P. Blakeman and B. Williamson, eds. CAB, Wallingford, U.K.

13. Hartman, J. R., Parisi, L., and Bautrais, P. 1999. Effect of leaf wetness duration, temperature, and conidial inoculum dose on apple scab infections. Plant Dis. 83:531-541.

14. Hau, B., and Kranz, J. 1990. Mathematics and statistics for analyses in epidemiology. Pages 15-22 in: Epidemics of Plant Diseases. J. Kranz, ed. Springer-Verlag, Berlin, Germany.

15. Hoagland, D. R., and Arnon, D. I. 1950. The water culture method for growing plants without soil. Calif. Agric. Exp. Stn., Circ. 347.

16. Jones, A. L. 1987. Role of wet periods in predicting foliar diseases. Pages 87100 in: Plant Disease Epidemiology: Population Dynamics and Management. Vol. 1. J. Leonard and W. E. Fry, eds. Macmillan Publishing Co., New York.

17. Lavee, S. 1990. Aims, methods, and advances in breeding of new olive (Olea europaea L.). Acta Hortic. 286:23-36.

18. Laviola, C. 1968. Aspetti biologici ed epifitologici di Spilocaea oleagina
(Cast.) Hugh. in Italia. Ann. Fac. Agraria Univ. Bari 22:345-360.

19. Longo, O., Ambrico, A., Schiavone, D., and Ciccarese, F. 2001. Comportamento di germoplasma di olivo verso l'"ochio di pavone". Italus Hortus 8:36-40.

20. López-Doncel, L. M. 2003. Evaluación de la resistencia del olivo a Spilocaea oleagina, agente del repilo. Ph.D. thesis. Universidad de Córdoba, Córdoba, Spain.

21. López-Doncel, L. M., García-Berenguer, A., and Trapero, A. 1999. Resistance of olive tree cultivars to leaf spot caused by Spilocaea oleagina. Acta Hortic. 474:549-553.

22. López-Doncel, L. M., Viruega, J. R., and Trapero, A. 2000. Respuesta del olivo a la inoculación con Spilocaea oleagina, agente del repilo. Bol. San. Veg. Plagas 26:349-363.

23. López-Doncel, L. M., Viruega, J. R., Zarco, A., and Trapero, A. 1995. Response of detached and attached olive leaves to infection by Spilocaea oleagina. Olea 23:125.

24. Loprieno, N., and Tenerini, I. 1960. Osservazioni sul ciclo biologico dell'agente patogeno dell'"occhio di pavone" dell'olivo (Cycloconium oleaginum Cast.). Soc. Montecatini, Milano, Italy.

25. MacHardy, W. E. 1996. Apple Scab: Biology, Epidemiology, and Management. American Phytopathological Society, St. Paul, MN.

26. Madden, L. V., Hughes, G., and van den Bosch, F. 2007. The study of plant disease epidemics. American Phytopathological Society, St. Paul, MN.

27. Magarey, R. D., Sutton, T. B., and Thayer, C. L. 2005. A simple generic infection model for foliar fungal plant pathogens. Phytopathology 95:92100.

28. Modugno, C. 1957. Primo contributo alle richerche su Cycloconium oleaginum Cast. e sul comportamento del parassita in oliveti del Lazio. Bol. Staz. Patol. Veg. 15:215-239.

29. Obanor, F. O., Walter, M., Jones, E. E., and Jaspers, M. V. 2007. Effect of temperature, relative humidity, leaf wetness and leaf age on Spilocaea oleagina conidium germination on olive leaves. Eur. J. Plant Pathol. 120:211-222.

30. Petri, L. 1913. Studi sulle malattie dell'olivo. Mem. R. Staz. Patol. Veg., Roma, Italy.

31. Roca, L. F., Viruega, J. R., López-Doncel, L. M., Moral, J., and Trapero, A. 2010. Métodos culturales, químicos y biológicos de control del Repilo. Vida Rural 304:38-42.

32. Saad, T., and Masri, S. 1978. Epidemiological studies on olive leaf spot incited by Spilocaea oleaginea (Cast.) Hughes. Phytopathol. Mediterr. 17:170-173.

33. Schubert, K., Ritschel, A., and Braun, U. 2003. A monograph of Fusicladium s. lat. (Hyphomycetes). Schlechtendalia 9:1-132.

34. Segura, R. 1996. Factores que influyen en la germinación de conidias de Spilocaea oleagina. Trabajo Profesional Fin de Carrera, ETSIAM, Universidad de Córdoba, Córdoba, Spain.

35. Shabi, E., Elisha, S., and Birger, R. 1994. The importance of spring infection of Spilocaea oleaginea in epidemiology of olive leaf spot. Phytoparasitica 22:85.

36. Tenerini, I. 1964. Richerche sulla biologia ed epidemiologia della Spilocaea oleaginea (Cast.) Hug., agente dell'occhio di pavone dell'olivo. Phytopathol. Mediterr. 3:63-70.

37. Trapero, A., and Blanco, M. A. 2008. Enfermedades. Pages 595-656 in: El Cultivo del Olivo. 5th ed. D. Barranco, R. Fernández-Escobar, and L. Rallo, eds. Junta de Andalucía/Mundi-Prensa, Madrid, Spain.

38. Trapero, A., and Roca, L. F. 2004. Bases epidemiológicas para el control integrado de los "Repilos" del olivo. Phytoma España 164:130-137.

39. Trapero-Casas, A., and Kaiser, W. J. 1992. Influence of temperature, wetness period, plant age, and inoculum concentration on infection and development of Ascochyta blight of chickpea. Phytopathology 82:589-596.

40. Viruega, J. R. 1999. Epidemiología del Repilo del olivo causado por Spilocaea oleagina Castagne (Hughes). Ph.D. thesis. Universidad de Córdoba, Córdoba, Spain.

41. Viruega, J. R., Luque-Márquez, F., and Trapero, A. 1997. Caída de aceitunas debida a infecciones del pedúnculo por Spilocaea oleagina, agente del repilo del olivo. Frutic. Prof. 88:48-54.

42. Viruega, J. R., Moreno, S., and Trapero, A. 2002. Efficacy of kresoximmethyl against olive scab caused by Spilocaea oleagina. Acta Hortic. 586:801-804

43. Viruega, J. R., and Trapero, A. 1999. Epidemiology of leaf spot of olive tree caused by Spilocaea oleagina in southern Spain. Acta Hortic. 474:531-534.

44. Viruega, J. R., and Trapero, A. 2002. Effect of temperature, wetness duration and leaf age on infection and development of olive leaf spot. Acta Hortic. 586:797-800.

45. Wilson, E. E., and Miller, H. N. 1949. Olive leaf spot and its control with fungicides. Hilgardia 19:1-24.

46. Yarwood, C. E. 1978. Water and the infection process. Pages 141-173 in Deficits and Plant Growth. Vol. V. T. T. Kozlowski, ed. Academic Press, New York.

47. Zarco, A., Viruega, J. R., Roca, L. F., and Trapero, A. 2007. Detección de las infecciones latentes de Spilocaea oleagina en hojas de olivo. Bol. San. Veg. Plagas 33:235-248.

48. Zayed, M. A., El-Saied, H. M., Ali, A. S., and Saied, K. S. 1980. Reaction of olive cultivars to Cycloconium oleaginum Cast., and chemical control of olive leaf spot disease in Egypt. Egyp. J. Phytopathol. 12:49-56. 